\title{
Mesoscale eddies influence distribution and aggregation patterns of micronekton in the Mozambique Channel
}

\author{
Philippe S. Sabarros ${ }^{1,2, *}$, Frédéric Ménard ${ }^{1}$, Jean-Jacques Lévénez ${ }^{3}$, \\ Emilie Tew-Kai ${ }^{1}$, Jean-François Ternon ${ }^{4}$ \\ ${ }^{1}$ Institut de Recherche pour le Développement (IRD), UMR 212 EME, Centre de Recherche Halieutique \\ Méditerranéenne et Tropicale (CRH), Avenue Jean Monnet, BP 171, 34203 Sète Cedex, France \\ ${ }^{2}$ Centre for Ecological and Evolutionary Synthesis (CEES), Department of Biology, University of Oslo, \\ PO Box 1066 Blindern, 0316 Oslo, Norway \\ ${ }^{3}$ IRD, US 004 ACCAPELLA, BP 70, 29280 Plouzané, France \\ ${ }^{4}$ IRD, UMR 212 EME, BP 172, 97492 Ste Clotilde Cedex, La Réunion, France
}

\begin{abstract}
Oceanic mesoscale circulation is a crucial structuring force in the marine environment. Dynamic processes associated with eddies, such as eddy-induced upwelling or eddy-eddy interaction, drive the transport and distribution of nutrients that support the whole food chain, presumably through bottom-up processes. Eddies can shape the distribution of organisms at both low (phytoplankton, zooplankton and fish larvae) and high trophic levels (top fish predators, seabirds or turtles), but the impact of mesoscale features on intermediate trophic levels (micronekton) remains poorly understood. We analysed the influence of eddies on the distribution of micronekton aggregations in the Mozambique Channel by combining data from acoustic surveys and satellite sea topography. We demonstrated that large aggregations of micronekton occurred mainly in areas where the local horizontal gradient of sea level anomalies is strong, i.e. at the periphery of eddies. We observed that, in this region, eddies running along the coast advect coastal nutrient-rich waters at their edges, which support the base of the food chain. We propose that eddies can shape the distribution and the aggregation patterns of the prey of marine top predators through bottom-up processes.
\end{abstract}

KEY WORDS: Mesoscale eddies · Micronekton · Sea level anomalies · Aggregating behaviour • Indian Ocean Resale or republication not permitted without written consent of the publisher

\section{INTRODUCTION}

Eddies are known to play a key role in the biological processes of pelagic ecosystems by converting physical energy into trophic energy (Bakun 2006). Eddies are pervasive and long-lived turbulent swirls in the ocean on scales of 10 to a few $100 \mathrm{~km}$ (Rhines 2001). These mesoscale features of the ocean are hotspots of biogeochemical and biological activity (Weimerskirch et al. 2004, Benitez-Nelson et al. 2007). Various mechanisms explain how eddies can fuel biological production in open-ocean ecosystems, leading to patches of enhanced productivity in zones of low primary production. Cyclonic eddies can generate upwelling of deepcold-nutrient-rich waters towards upper euphotic surface layers in their centre (McGillicuddy et al. 1998, Bakun 2006), enhancing local primary production (Seki et al. 2001, Mizobata et al. 2002, Benitez-Nelson et al. 2007). Anticyclonic eddies can also generate an upward movement of rich waters, but located around their edge, where phytoplankton enrichment has also been observed (Mizobata et al. 2002, Quartly \& Srokosz 2004). Eddies influence the transport and distribution of nutrients and can thereby spatially struc- 
ture the biological activity over the different trophic levels of the pelagic food chain. Several studies have demonstrated that eddies markedly enhanced geochemical transformations and primary production in the subtropical Pacific Ocean (Seki et al. 2001, BenitezNelson et al. 2007), in the Atlantic Ocean (McGillicuddy et al. 1998, Garçon et al. 2001), in the Bering Sea (Mizobata et al. 2002) and in the Indian Ocean (Quartly \& Srokosz 2004, Waite et al. 2007). Mesoscale eddies also affect the upper-trophic-level organisms by influencing the horizontal and vertical distribution of mesozooplankton and fish larvae (Bakun 2006, Muhling et al. 2007), affecting movement patterns of turtles (Polovina et al. 2004, Lambardi et al. 2008), attracting tuna (Young et al. 2001) or swordfish (Seki et al. 2002), and influencing the foraging strategy of seabirds (Nel et al. 2001, Weimerskirch et al. 2004, Hyrenbach et al. 2006).

Micronekton consists of small organisms (fish, crustaceans and cephalopods) and is the trophic link between zooplankton and top predators in open-sea ecosystems. To our knowledge, little attention has been paid to the way mesoscale oceanographic features shape the aggregations of micronekton organisms, i.e. the prey of pelagic predators. Here, we present evidence from acoustic surveys and satellite data showing that the distribution of micronekton aggregations in the Mozambique Channel (southwestern Indian Ocean) is affected by mesoscale eddies. The circulation in the Mozambique Channel is indeed ruled by an important mesoscale activity: large cyclonic and anticyclonic eddies propagate southwards along the western edge of the channel (de Ruijter et al. 2002, Schouten et al. 2003, Quartly \& Srokosz 2004). The spatial overlap between the foraging areas of great frigatebirds and eddies in the Mozambique Channel have already been suggested to be related to high prey availability (Weimerskirch et al. 2004), but a link between the prey of pelagic top predators and mesoscale eddies has not been demonstrated previously.

\section{MATERIALS AND METHODS}

Acoustic data. Four cruises were carried out in the French Exclusive Economic Zone (EEZ) of the Mozambique Channel (southwestern Indian Ocean) between September 2002 and November 2004 onboard 2 vessels: the RV 'La Curieuse' of the French Institut Paul Emile Victor (IPEV) and the French longliner 'Cap Morgane' (Fig. 1). Acoustic data were collected with a SIMRAD EK60 echo sounder with a $38 \mathrm{kHz}$ split-beam transducer on all cruises. The transducer was mounted $3 \mathrm{~m}$ below the water surface on a pole fixed on the port side of the vessel. The water column was sampled down to a depth of $800 \mathrm{~m}$. Raw data were processed using Movies+ software (Weill et al. 1993). The acoustic back-scattering energy was converted to nautical area scattering coefficient $\left(\mathrm{s}_{\mathrm{A}}\right.$, in $\left.\mathrm{m}^{2} \mathrm{~nm}^{-2}\right)$ and integrated in elementary sampling distance units (ESDU) of $1 \mathrm{~nm}$. The integration threshold was set at $-80 \mathrm{~dB}$. At $38 \mathrm{kHz}, \mathrm{s}_{\mathrm{A}}$ is representative of the micronekton abundance (Bertrand et al. 1999). Echograms graphically represent the acoustic back-scattered energy; micronekton aggregations can be tracked on echograms.

Morphological coding of the echograms was undertaken visually using the method proposed by Petitgas \& Lévénez (1996). Echo type discrimination was performed horizontally for each $5 \mathrm{~nm}$ and in the intermediate depth layer (100 to $400 \mathrm{~m}$ ) only, since micronekton aggregations occurred exclusively in this depth range. Four echo types were defined (Fig. 2a): absence of an echo trace (ET.1), scattered fish or small aggregates (ET.2), large aggregated structures (ET.3) and scattering layer (ET.4). Each echo type was classified according to time: day, dusk, night and dawn. We chose to remove the few observations made during dusk and dawn from the analyses. Echo type ET.4 occurred quasi-exclusively during the transitional phases (i.e. dusk and dawn) of which ET.4 is typical; we also removed the few observations of ET.4 during the day and at night. Acoustic data finally consisted of 651 observations of 3 echo types (ET.1, ET.2, ET.3), of which $55 \%$ were collected during the day and $45 \%$ at night.

Altimetry data. Mesocale hydrographic eddies can efficiently be defined in terms of sea level anomalies (SLA), but we assumed that the slope of the sea (i.e. the gradient) was a better indicator of local mesoscale dynamics than the raw SLA values (Ménard et al. 2005). We used merged SLA data from 5 satellite products (TOPEX/Poseidon, ERS-2, GFO, Jason-1 and ENVISAT) produced by Ssalto/Duacs and distributed in near real time (i.e. 1 map every 3.5 d) by AVISO (www.aviso.oceanobs.com) with support of CNES (Centre Nationale d'Etudes Spaciales, France). SLA data are provided with a spatial resolution of $1 / 4^{\circ}$ latitude/longitude (i.e. $15 \mathrm{~nm}$ ). The local SLA gradient index $\left(\mathrm{cm} \mathrm{deg}{ }^{-1}\right)$ was defined as the norm of the SLA gradient vector, computed along the zonal and meridional directions. The value of this index is high at the edge of the eddies, particularly in the frontal zone between a cylonic (negative anomaly) and an anticyclonic eddy (positive anomaly) (see Fig. 1). A value of the local gradient index, computed from the interpolated maps of SLA, was then assigned to each of the acoustic observations performed on intervals of $5 \mathrm{~nm}$.

Statistical analysis. A proportional-odds model for ordinal response (McCullagh \& Nelder 1989) was fitted 

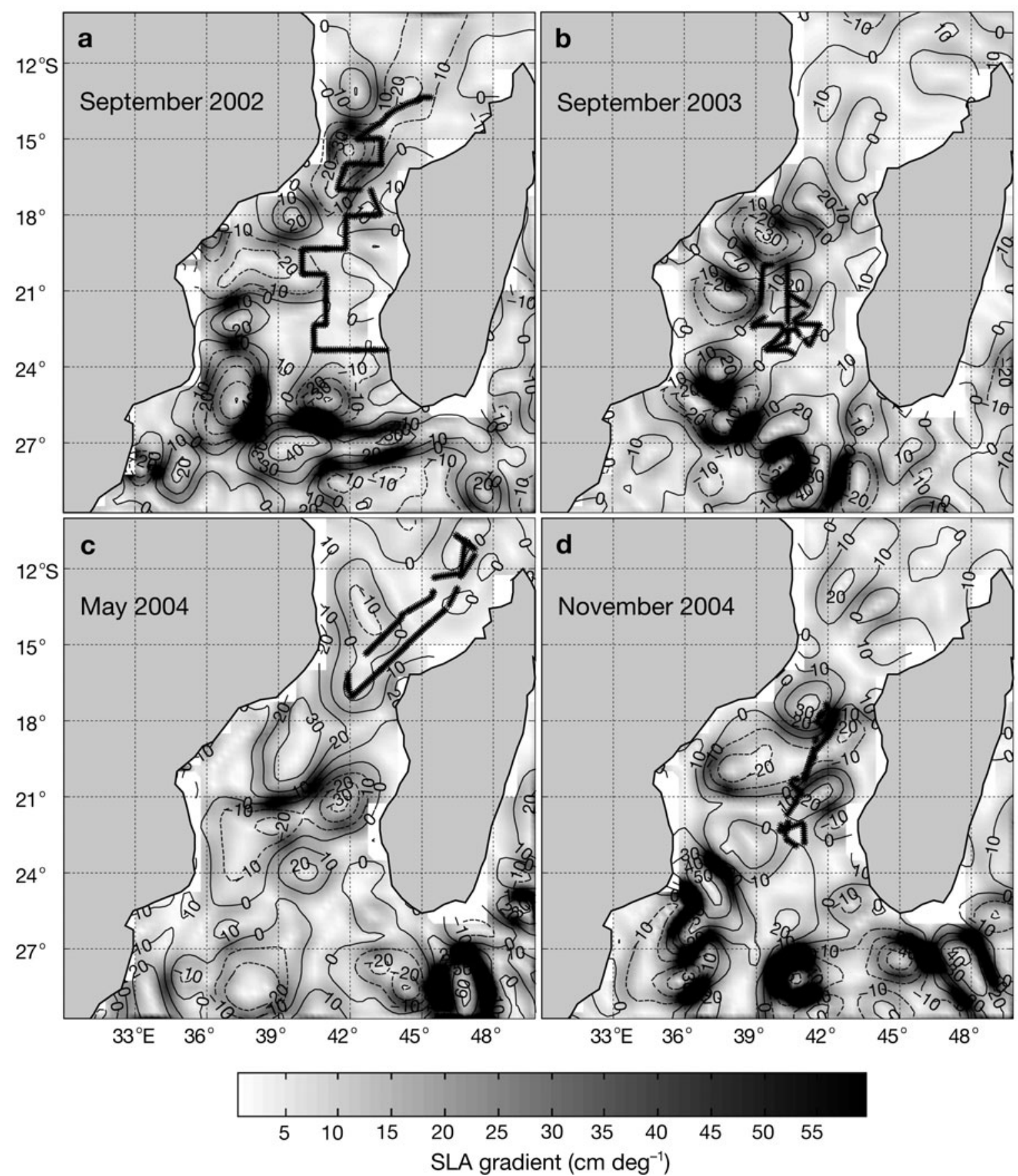

Fig. 1. ECOTEM cruise tracks in the Mozambique Channel with sea topography at the time of each cruise. Contour lines represent sea level anomalies (SLA, cm); full contours indicate anticyclonic eddies and broken contours indicate cyclonic features. Grey shading indicates local SLA gradient $\left(\mathrm{cm} \mathrm{deg}^{-1}\right)$. (Line of asterisks) Hydroacoustic transects: 1370 elementary distance sampling units (EDSU) were prospected during ECOTEM5 (17 d, $12^{\circ}$ to $24^{\circ} \mathrm{S}$, RV 'La Curieuse') in September 2002,790 EDSUs during ECOTEM9 in September 2003 (24 d, 19 to 24 $\mathrm{S}$, Cap Morgane), 939 EDSUs during ECOTEM6 in May 2004 (19 d, $11^{\circ}$ to $18^{\circ} \mathrm{S}$, Cap Morgane), and 760 EDSUs during ECOTEM7 in November 2004 ( $20 \mathrm{~d}, 7^{\circ}$ to $24^{\circ} \mathrm{S}$, Cap Morgane)

to the vector of echo type observations $\left(y_{i}\right)_{i \geq 1}$ that was assumed to be a realization of a random variable $Y . Y$ takes its values in the set $\mathrm{E}=\{\mathrm{ET} .1, \mathrm{ET} .2, \mathrm{ET} .3\}$ of 3 ordered categories. The model was written in terms of the cumulative probability function of $Y$, conditional on 2 observed exogenous covariates: the time period $T$ that takes its values in the set $\mathrm{F}=\{$ day, night $\}$; and the continuous variable $X$ representing the local SLA gradient values $\left(x_{i}\right)_{i \geq 1}$. The logistic form was chosen. For $j$ $\in \mathrm{E}$ and $k \in \mathrm{F}$, the probability distribution $(\operatorname{Pr})$ is written: 


\section{(a) Echo traces}

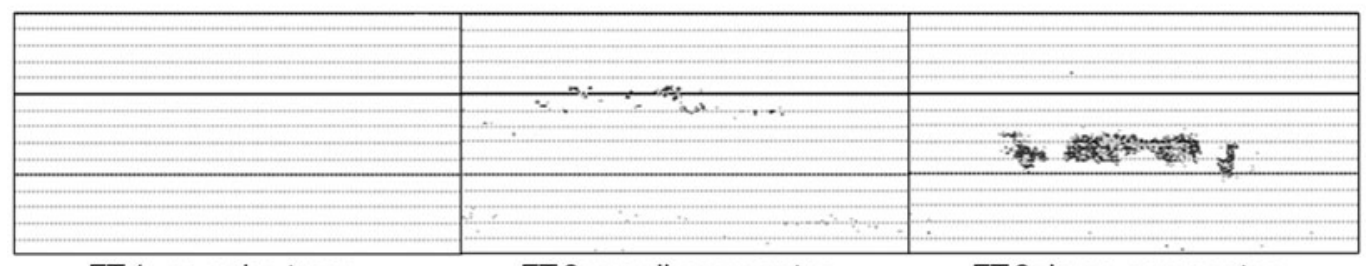

ET.1: no echo trace

ET.2: small aggregates

ET.3: large aggregates

(b) Day

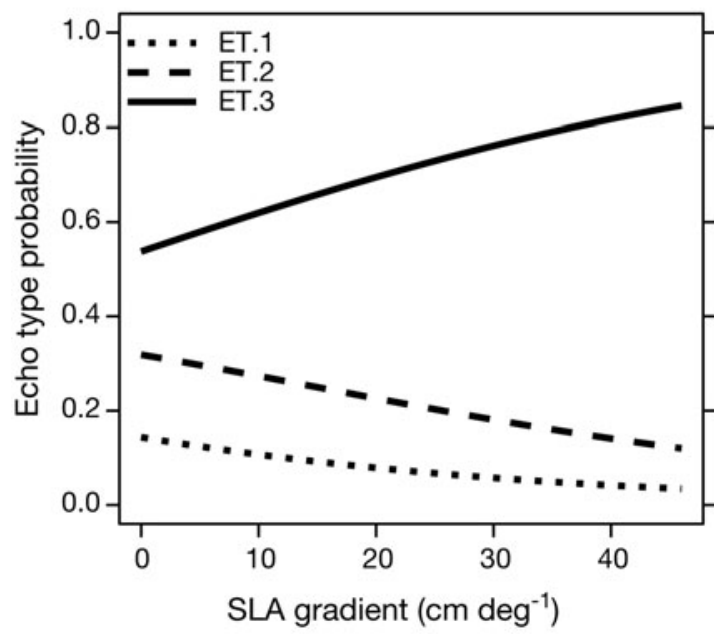

(c) Night

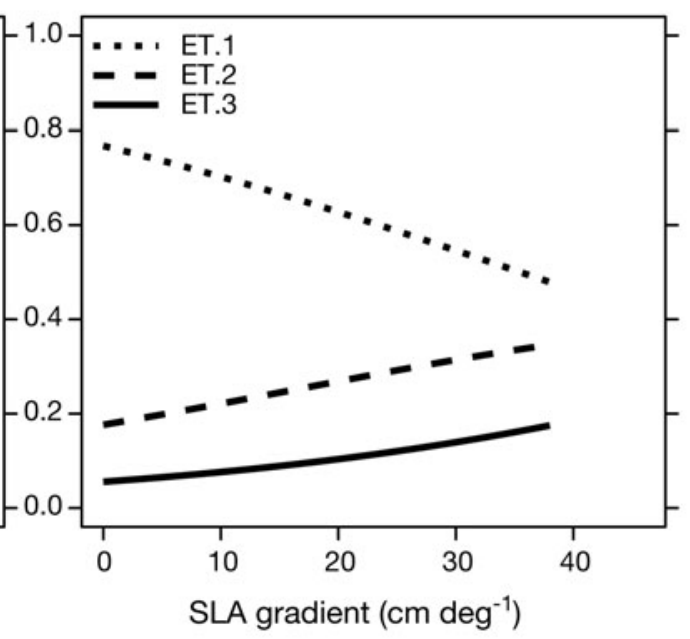

Fig. 2. (a) Echo traces of the 3 selected echo types of the intermediate layer (100 to $400 \mathrm{~m}$ ) and their occurrence probabilities (as output of the proportional odds model) as a function of the local sea level anomalies (SLA) gradient (b) during the day and (c) at night. (…...) ET.1 no echo trace, (- - - -) ET.2 scattered fish or small aggregates, and (-) ET.3 large aggregates

$$
\operatorname{logit}\left[\operatorname{Pr}\left(Y \leq j \mid T=k_{1} X=x\right)\right]=\lambda_{j}-\alpha I_{T}-\beta x_{1}
$$

where logit is the logistic function and $\lambda_{j}, \alpha$ and $\beta$ are the unknown parameters to be estimated. $\lambda_{\mathrm{s}}\left(\lambda_{1}\right.$ and $\left.\lambda_{2}\right)$ are the intercept parameters, $\alpha$ is the effect of the time period, represented by the indicator variable $\mathrm{I}_{T}\left(\mathrm{I}_{T}=1\right.$ if $k=$ night and 0 otherwise), and $\beta$ is the regression coefficient on the local SLA gradient. The probability of observing a given echo type was computed by taking the difference of the cumulative response probabilities (with $\operatorname{Pr}(Y \leq 0 \mid T=k, X=x)=0$ and $\operatorname{Pr}(Y \leq$ ET.3 । $T=k, X=x)=1)$.

We first performed analyses for each individual cruise; however, few data were collected on some cruises, and ranges of SLA gradient were sometimes narrow. Indeed, the sea topography was not taken into account while planning the cruise tracks. Therefore, we fitted the model using all data collected during the 4 cruises to allow for variable topographic situations. The Akaike Information Criterion (AIC) was used to select the most parsimonious model. Significance of the contribution of each covariate to the final model was checked by performing a Type III ANOVA. The observations recorded along the transect could not be considered to be spatially independent. Autocorrelation along hydroacoustic transects was tested with the autocorrelation function and found to be significant up to 3 spatial lags (i.e. $15 \mathrm{~nm}$ ). To examine this further, we added the echo type observations to the model as covariates, lagged by 1 to 3 to explicitly acknowledge any spatial autocorrelation. We found that this did not change the type and significance of the effects we initially tested (diel phase and local SLA gradient). Statistical analyses were conducted with R (R Development Core Team 2007) using the polr function in the MASS package (Venables \& Ripley 2002).

\section{RESULTS}

According to AIC, the proportional odds model with 2 covariates (i.e. diel period and local SLA gradient) was better than the models with a single covariate $\left(\mathrm{AIC}_{T_{1} X}=1068\right.$ vs. $\mathrm{AIC}_{T}=1080$ and $\left.\mathrm{AIC}_{X}=1373\right)$. The 
Type III ANOVA confirmed that the effect of the time period was significant $\left(\mathrm{LR} \mathrm{Chi}^{2}=307.93, \mathrm{DF}=1, \mathrm{p}<\right.$ 0.05), as well as the local SLA gradient $\left(\mathrm{LR} \mathrm{Chi}^{2}=\right.$ 14.87, DF $=1, p<0.05)$. The estimated values of the parameters are given in Table 1. To illustrate how the local SLA gradient influences the occurrence of micronekton aggregates, we computed the probabilities of observing each echo type as a function of the diel phase (day and night) and of the SLA gradient (Fig. $2 \mathrm{~b}, \mathrm{c}$ ). In both time periods, increasing values of the SLA gradient led to a sharp increase in the probability of occurrence of large micronekton aggregations (ET.3) and to a marked decrease of the probability of observing no echo trace (ET.1). The occurrence probability of ET.3 was always higher during daytime than during the night, whereas the opposite trend was observed with ET.1. The ranges of variation of the probability of observing scattered fish and small aggregates (ET.2) were close during the 2 diel phases, and SLA gradient exerts an opposite influence: positive during the night and negative during the day.

\section{DISCUSSION}

By combining acoustic data and satellite altimetry data, our results showed that eddies influence the occurrence and pattern of aggregation of the micronekton in the Mozambique Channel. During daytime, the micronekton gathers into large aggregations along the edge of interacting cyclonic (negative anomaly) and anticyclonic (positive anomaly) features (high SLA gradient values, Fig. 3) rather than in low energetic areas, e.g. within eddies. At night, most micronekton organisms migrate towards the surface layer (e.g. Lebourges-Dhaussy et al. 2000), and the few organisms that remain in the intermediate layer form small aggregates. In addition to the usual central eddy pumping mechanism, observational and process-modelling studies have shown an enhancement of primary production and an accumulation of biomass on the

Table 1. Estimated parameter values (+SE) produced by the proportional odds model. $t$ is the statistic given by the model and $\mathrm{p}$ indicates the significance of the respective effects. Parameters: $\lambda_{1}$ and $\lambda_{2}$, intercepts when the cutpoint is, respectively, set between level 1 and 2, and between level 2 and 3 of the echo type response variable; $\alpha$, effect of the diel phase; $\beta$, regression parameter for the sea level anomalies gradient

\begin{tabular}{|lrrrr|}
\hline Parameter & Estimate & SE & \multicolumn{1}{c|}{$t$} & \multicolumn{1}{c|}{$\mathrm{p}$} \\
\hline$\lambda_{1}$ & -1.7843 & 0.2026 & -8.8062 & $<0.05$ \\
$\lambda_{2}$ & -0.0041 & 0.1768 & -0.8502 & 0.18 \\
$\alpha$ & -2.9797 & 0.1911 & -15.5956 & $<0.05$ \\
$\beta$ & 0.0337 & 0.0089 & 3.7694 & $<0.05$ \\
\hline
\end{tabular}

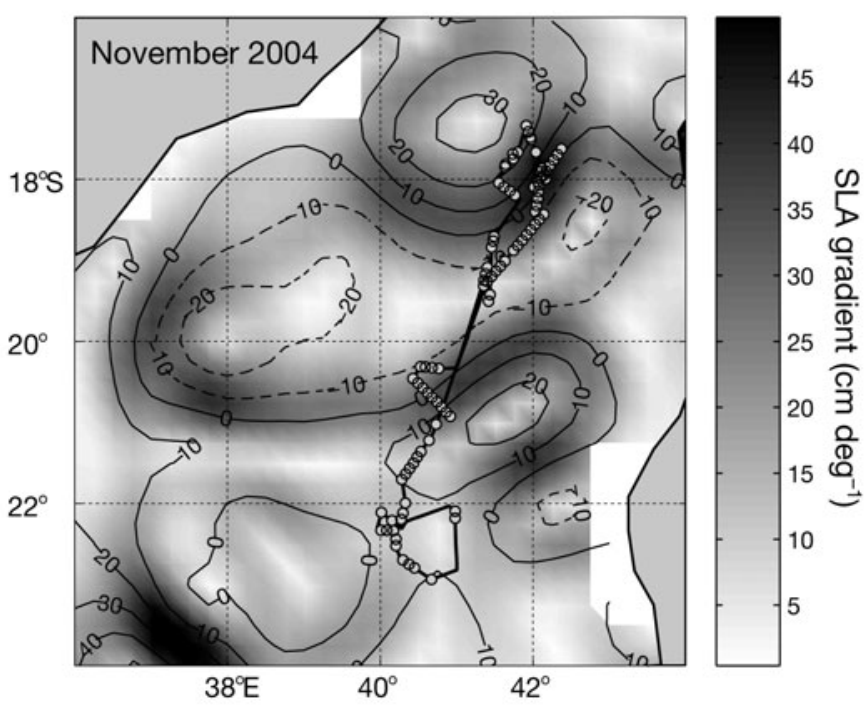

Fig. 3. Location of ET.3 observations (light dots) during ECOTEM7 cruise conducted in November 2004. Full line represents the complete cruise track. Contour lines represent sea level anomalies (SLA) (cm) on 11 November 2004. Grey shading indicates local SLA gradient $\left(\mathrm{cm} \mathrm{deg}^{-1}\right)$. Note the concentration of ET.3 in high local SLA gradient areas, particularly around $18^{\circ} \mathrm{S}, 42^{\circ} \mathrm{E}$. See 'Acoustic data', 'Materials and methods' for definition of echo types

edges of anticylonic eddies (Mizobata et al. 2002) and at eddy-eddy interactions (Lima et al. 2002). Eddies in the Mozambique Channel tend to advect coastal waters at their periphery when they run along the coast (Tew-Kai \& Marsac 2008) and are thereby able to drain a significant amount of nutrient-rich waters towards the middle of the channel. Large micronekton aggregations are infrequent whithin eddies (low SLA gradient values), although high primary production can be observed at the centre of cyclonic eddies (Lima et al. 2002). The micronekton detected by acoustic methods could not be identified; however, we assumed that the aggregations were taxonomically diverse and included fish, cephalopods, and crustaceans. Our findings provide first evidence that mesoscale eddies can shape the aggregation patterns of the prey of top pelagic predators in this region. Indeed, large fish predators such as tuna feed on various micronektonic organisms ranging from 2 to a few 10s of cm, including numerous fish, squid and crustacean species (Young et al. 2001, Ménard et al. 2006, Potier et al. 2007). Piscivorous predators hunt individual prey but commonly seek out micronekton aggregations, such as shoals and clusters of shoals, in the water column (LebourgesDhaussy et al. 2000, Bertrand et al. 2002). Therefore, schooling behaviour of prey organisms plays a major role in the feeding success of marine fish predators that roam the open sea, often in shoals (Ménard \& Marchal 2003). Advection of coastal nutrient-rich waters 
and eddy-eddy interactions likely enhance biological production in otherwise poor waters, sustaining stocks of potential prey for micronektonic species through bottom-up processes. The micronekton, in turn, can be sought out by upper trophic level predators such as tuna and tuna-like species (Seki et al. 2002, Domokos et al. 2007), turtles (Polovina et al. 2004, Lambardi et al. 2008) or seabirds (Nel et al. 2001, Weimerskirch et al. 2004, Hyrenbach et al. 2006). Indeed, several tropical seabird species rely to a large extent on the association with subsurface predators such as tuna, which concentrate prey organisms at the surface while hunting, thus allowing birds to snatch their prey at or above the sea surface (Le Corre \& Jaquemet 2005). At present, the exact process that concentrates aggregations of intermediate trophic level species at the periphery of eddies is unknown. Satellites can survey the top water layer (e.g. phytoplankton production). Satellites only offer an understanding of the surface mesoscale activity. This is not enough to understand the biophysical processes associated with the mesocale features. Further studies are required to better investigate the biophysical coupling in mesoscale eddies, such as process studies with 3D eddy-resolving models and field investigations combining diet analysis of top predators with acoustic data and pelagic trawling.

Acknowledgements. The authors thank the crews of RV 'La Curieuse' and the longliner 'Cap Morgane' for help with sample collection. This work was entirely funded by the French Institut de Recherche pour le Développement (IRD). We thank Marie Curie Actions under FP6 (MEST-CT-2005-020932) for additional support to P.S.S. at the CEES-MCO training site. We also thank H. Demarcq, E. Josse, F. Marsac and E. Edeline for their wise comments and helpful suggestions. We are also thankful to the 2 anonymous reviewers who helped to finalize the manuscript.

\section{LITERATURE CITED}

Bakun A (2006) Fronts and eddies as key structures in the habitat of marine fish larvae: opportunity adaptive response and competitive advantage. Sci Mar 70:105-122

Benitez-Nelson CR, Bidigare RR, Dickey TD, Landry MR and others (2007) Mesoscale eddies drive increased silica export in the Subtropical Pacific Ocean. Science 316:1017-1021

- Bertrand A, Le Borgne R, Josse E (1999) Acoustic characterisation of micronekton distribution in French Polynesia. Mar Ecol Prog Ser 191:127-140

Bertrand A, Bard F, Josse E (2002) Tuna food habits related to the micronekton distribution in French Polynesia. Mar Biol 140:1023-1037

de Ruijter WPM, Ridderinkhof H, Lutjeharms JRE, Schouten MW, Veth C (2002) Observations of the flow in the Mozambique Channel. Geophys Res Lett 29:1502

> Domokos R, Seki MP, Polovina JJ, Hawn DR (2007) Oceanographic investigation of the American Samoa albacore (Thunnus alalunga) habitat and longline fishing grounds. Fish Oceanogr 16:555-572
Garçon V, Oschlies A, Doney S, McGillicuddy D Jr, Waniek J (2001) The role of mesoscale variability on plankton dynamics in the North Atlantic. Deep-Sea Res II 48: 2199-2226

Hyrenbach KD, Veit RR, Weimerskirch H, Hunt Jr GL (2006) Seabird associations with mesoscale eddies: the subtropical Indian Ocean. Mar Ecol Prog Ser 324:271-279

Lambardi P, Lutjeharms JRE, Mencacci R, Hays GC, Luschi P (2008) Influence of ocean currents on long-distance movement of leatherback sea turtles in the Southwest Indian Ocean. Mar Ecol Prog Ser 353:289-301

> Le Corre M, Jaquemet S (2005) Assessment of seabird community of the Mozambique Channel and its potential use as indicator of tuna abundance. Estuar Coast Shelf Sci 63: $421-428$

> Lebourges-Dhaussy A, Marchal E, Menkes C, Champalbert G, Biessy B (2000) Vinciguerria nimbaria (micronekton), environment and tuna: their relationship in the Eastern Tropical Atlantic. Oceanol Acta 23:515-527

> Lima ID, Olson DB, Doney SC (2002) Biological response to frontal dynamics and mesoscale variability in oligotrophic environments: biological production and community structure. J Geophys Res C 107(C8)

McCullagh P, Nelder J (1989) Generalized linear models, 2nd edn. Chapman \& Hall, London

McGillicuddy DJ Jr, Robinson AR, Jannasch HW, Johnsonk R, Michaels TAF, Knapk AH (1998) Influence of mesoscale eddies on new production in the Sargasso Sea. Nature 394:263-266

Ménard F, Marchal E (2003) Foraging behaviour of tuna feeding on small schooling Vinciguerria nimbaria in the surface layer of the equatorial Atlantic Ocean. Aquat Living Resour 16:231-238

Ménard F, Levenez JJ, Potier M, Ternon JF, Baurand $F$, Maury O, Marsac F (2005) Acoustic characterization of tropical tuna prey in the Western Indian Ocean in relation with local environmental conditions. ICES CUM 2005U11, International Council for the Exploration of the Sea, Aberdeen

> Ménard F, Labrune C, Shin Y, Asine A, Bard F (2006) Opportunistic predation in tuna: a size-based approach. Mar Ecol Prog Ser 323:223-231

> Mizobata K, Saitoh S, Shiomoto S, Miyamura T and others (2002) Bering Sea cyclonic and anticyclonic eddies observed during summer 2000 and 2001. Prog Oceanogr 55:65-75

> Muhling BA, Beckley LE, Olivar MP (2007) Ichthyoplankton assemblage structure in 2 meso-scale Leeuwin Current eddies, eastern Indian Ocean. Deep-Sea Res II 54: 1113-1128

Nel DC, Lutjeharms JRE, Pakhomov EA, Ansorge IJ, Ryan PG, Klages NTW (2001) Exploitation of mesoscale oceanographic features by grey-headed albatross Thalassarche chrysostoma in the southern Indian Ocean. Mar Ecol Prog Ser 217:15-26

Petitgas P, Lévénez JJ (1996) Spatial organization of pelagic fish: echogram structure, spatio-temporal condition, and biomass in Senegalese waters. ICES J Mar Sci 53:147-153

Polovina JJ, Balazs GH, Howell EA, Parker DM, Seki MP, Dutton PH (2004) Forage and migration of loggerhead (Caretta caretta) and olive ridley (Lepidichelys olivacea) sea turtles in the central North Pacific Ocean. Fish Oceanogr 13:36-51

> Potier M, Marsac F, Cherel Y, Lucas V, Sabatié R, Maury O, Ménard F (2007) Forage fauna in the diet of 3 large pelagic fish (lancetfish, swordfish, and yellowfin tuna) in the western equatorial Indian Ocean. Fish Res 83:60-72 
Quartly G, Srokosz M (2004) Eddies in the southern Mozambique Channel. Deep-Sea Res II 51:69-83

R Development Core Team (2007) R: a Language and environment for statistical computing. R Foundation for Statistical Computing, Vienna

Rhines PB (2001) Mesoscale eddies. In: Steele JH, Turekian KK, Thorpe SA (eds) Encyclopedia of ocean sciences. Academic Press, London, p 1717-1730

Schouten MW, de Ruijter WPM, van Leeuwen PJ, Ridderinkhof $\mathrm{H}$ (2003) Eddies and variability in the Mozambique Channel. Deep-Sea Res II 50:1987-2003

Seki MP, Polovina JJ, Brainard RE, Bidigare RR, Leonard CL (2001) Biological enhancement at cyclonic eddies tracked with GOES thermal imagery in Hawaiian waters. Geophys Res Lett 28:1583-1586

Seki MP, Polovina JJ, Kobayashi DR, Bididgare RR, Mitchum GT (2002) An oceanographic characterization of swordfish (Xiphias gladius) longline fishing grounds in the springtime subtropical North Pacific. Fish Oceanogr 11: 251-266

Submitted: April 14, 2008; Accepted: April 28, 2009
Tew-Kai E, Marsac F (2008) Patterns of variability of sea surface chlorophyll in the Mozambique Channel: a quantitative approach. J Mar Syst 77:77-88

Venables WN, Ripley BD (2002) Modern applied statistics with S. 4th edn. Springer, New York

Waite AM, Thompson PA, Pesant S, Feng M and others (2007) The Leeuwin Current and its eddies: an introductory overview. Deep-Sea Res II 54:789-796

Weill A, Scalabrin C, Diner N (1993) MOVIES-B: an acoustic detection description software. Application to shoal species' classification. Aquat Living Resour 6:255-267

Weimerskirch H, Le Corre M, Jaquemet S, Potier M, Marsac F (2004) Foraging strategy of a top predator in tropical waters: great frigatebirds in the Mozambique Channel. Mar Ecol Prog Ser 275:297-308

Young JW, Bradford R, Lamb TD, Clementson LA, Kloser R, Galea H (2001) Yellowfin tuna (Thunnus albacares) aggregations along the shelf break off south-eastern Australia: links between inshore and offshore processes. Mar Freshw Res 52:463-474

Proofs received from author(s): July 20, 2009 